Vidyodaya J., of Sci., (1992) Vol. 4, No. 1, pp. 1 - 31

REVIEW

\title{
FIFTY YEARS OF QUALITY TECHNOLOGY
}

\author{
R. A. Dayananda \\ Department of Mathematics, \\ University of Sri Jayewardenepura, \\ Nugegoda, Sri Lanka.
}

Received on : 15-7-1992

Accepted on : 20-9-1992

Generally speaking the so called development we are enjoying today would have been accelerated by the second world war; this is particularly true for today's quality technology. So we begin with the war period. It is fairly obvious that development of quality technology got a boost due to the demanding position it faced by the war. One might say that the first revolution in the quality technology took place during the war time and immediately before ; and the second has begun about a decade ago. Therefore we are, in this paper, concentrating mainly on the said two periods.

The subject Statistics is fairly young but "quality" terminology would have been there with the mankind since its civilization. However at present Statistics plays as a great tool in the field of quality technology of today. The main role of Statistics has been to produce most economic quality rather than the quality at any cost happening before "Statistics" came into the picture.

In this review paper we are proposing to discuss some interesting historical development as well as current advancement in the subject.

Quality of manufactured goods dates back to ancient Egypt (see Juran J. M. and Gryna, F. M. Jr. 1970) while the earliest application of Statistics in quality control is as old as 1920 pioneered by Dr. Waiter Shewart and his associates at the Bell Laboratories and Western Electric $(1931,1939)$. Thanks to Shewart, Quality Control became an Engineering discipline. It helped out to fend off the depression existing in the Western World at that time (see Blanton Godfrey 1986). According to Ishikawa (1976), the whole philosophy of quality improvement is, there is always a better way of doing things. The way is associated with the scientific method of data collection, data analysis experimentation as a catalyst for our engineering and other knowledge.

As spelled out in Box and Bisgaard (1987) "every process generates information that can be used to improve the process. e.g. when a product fails it also produces information that can be used (that it failed and under what circumstances) to find the cause for failure. 


\subsection{History of the use of Design of Experiments in Quality Industry}

Inspite of the rules of thumb that have been applied in the past to improve quality of products, one of the first persons to have recognized the place of design of experiments in quality control was L.H.C. Tippett $(1938,1950)$. He worked for British cotton industry and his association with Fisher made him to break the tradition of varying only one factor at a time. He infact bravely used factorial experiments idea. This method followed by fractional factorials and orthogonal arrays by British, Indian and American scientists, provided great savings in experimental effort. Fisher's method also provides more information about the system studied than traditional, one at a time experiments.

In 1938 Massachusett's Institute of Technology (MIT) sponsored an "Industrial Statistics Conference" with participants coming mainly from the United States and the Great Britain. Among the speakers were Shewart, Leslie E. Simon, S. S. Wilks (see 1938, 1941, 1971, 1938, 1942). At this conference Tippett presented two very extensive lectures on the use of statistical methods : (1) "The statistical principles of experimentation, with particular reference to experimentation in textile factories" and (2) "Statistical aspects of the control of quality in textile manufacture". These lectures which were later published, showed how important the role of design of experiments was in the statistical methods of the quality control and improvement. $\mathrm{He}$ was invited again after the second World War back to MIT. His work is preserved in an interesting book titled "Technological Applications of Statistics" published in 1950 .

\subsection{Deming's Contribution to World of Quality}

One of the great men of quality engineering and management could easily be named as Deming. William Edwards Deming is still living in his nineties and is still helping the world to keep it going with the quality products. $\mathrm{He}$ has been once referred to as "the Father of the Third Wave of the Industrial Revolution", and then as the "Japanese secret" though he himself is not a Japanese but an American for the greatest contribution he has made towards the highest achievement in quality in the manufactured products today in Japan. It is an interesting story how it all happened. In 1942, Deming was asked to set up some courses to teach quality control methods to industrialists, engineers inspectors, etc. particularly involved in the war effort. The programme had a strongly beneficial effect on both the quality and volume of production; spectacular reduction in scrap and the need for rework were. made. He pioneered the begining of American Society for Quality Control at that time. However the advances made during the war were not sustained subsequently. American manufacturers found themselves in a boom sellers market - any thing they produced was readily sellable. Why then bother with quality? Deming realized with great regret that his mistake had been to fail to get his 
message through to management. To quote him, "The courses were well received by engineers, but management paid no attention to them. Management did not understand that they had to get behind improvement of quality and carry out their obligations from the top to down. Any instabilities can help to point out specific times or locations of local problems. Once these local problems are removed, there is a process that will continue until somebody changes it. Changing the process is the management's responsibility. And we failed to teach them that."

He was later invited to give a lecture course to Japanese research workers, plant managers, and engineers on quality control methods, which he very happily accepted. However, following his experience with American industry, he made one vital change. Once he was there, he did seek a particular audience. He said that, in addition to the meetings JUSE (The Union of Japanese Scientists and Engineers) had organised, he also had to speak with Japan's chief executives. This first occurred on 13 July 1950, the presidents of 21 leading companies were invited. They all came. During that summer, he spoke to about 100 such industrial leaders. In 1951 he reached about 400 more. It seems that, in America, the first cheif executive to listen to him was William E Conway of the Nashua Corporation. And that was not until 1979!

\subsection{Deming's philosophy}

According to Deming the most important part of the production line is the customer, which nobody will challenge. However the statements like "satisfying the customer at the lowest cost" does not belong to Deming's philosophy. It will not suffice to have customers that are merely satisfied. An unhappy customer will switch. Unfortunately, a satisfied customer may also switch, on the theroy that he could not lose much, and might gain.Profit in business comes from repeat customers, cutomers that boast about your products and service, and that bring friends with them. Deming also speaks of staying ahead of the customer. The customer does not know what he will need one, three, five years from now. If, you as the supplier, wait till then to find out, you will hardly be ready to serve him. In a nutshell following is the Deming's approach to quality production.

\subsection{Deming's 14 Points for Management}

\section{(I) Constancy of Purpose}

Create constancy of purpose for continual improvement of products and service, allocating resources to provide for long range needs rather than only short term profitability, with plan to become competitive, to stay in business, and to provide jobs. 
(2) The New Philosophy

Adopt The new philosophy. We are in a new economic age, created by Japan. We can no longer live with commonly accepted levels of delays, mistakes, defective materials, and defective workmanship. Transformation of western management style is necessary to halt the continued decline of industry.

\section{(3) Cease Dependence on Masss Inspection}

Eliminate the need for mass inspection as a way to achieve quality by building quality into the product in the first place. Require statistical evidence of built-in quality in both manufacturing and purchasing functions.

\section{(4) End Lowest Tender Contracts}

End the practice of awarding business solely on the basis of price tag. Instead, require meaningful measures of quality with statistical evidence of quality. Move towards a single supplier for any one item, on a long-term relationship of loyalty and trust. The aim is to minimize total cost, not merely initial cost. Purchasing managers have a new job, and must learn it.

\section{(5) Improve Every Process}

Improve constantly and for ever every process for planning, production and service. Search continually for problems in order to improve every activity in the company, to improve quality and productivity, and thus to constantly decrease costs. It is management's job to work continually on the system (design, incoming materials, maintenance, improvement of machines, supervision, training, retraining).

(6) Institute Training on the Job

Institute modern methods of training on the job for all, including management, to make better use of every employee. New skills are required to keep up with changes in materials, methods, product design, machinery, techniques and service.

(7) Institute Leadership

Adopt and institute leadership aimed at people to do a better job. The responsibility of managers and supervisors must be changed from sheer numbers to quality. Improvement of quality will automatically improve productivity, Management must ensure that immediate action is taken on report of inherited defects, maintenance requirements, poor tools, fuzzy operational definitions, and other conditions detrimental to quality. 
(8) Drive out Fear

Encourage effective two-way communication and other means $t$.) drive out fear throughout the organisation so that everybody may work effectively and more productively for the company.

\section{(9) Break Down Barriers}

Break down barriers between departments and staff areas. People in different areas such as Research, Design, Sales, Administration, and Production must work in teams to tackle problems that may be encountered with products or service.

\section{(10) Eliminate Exhortations}

Eliminate the use of slogans, posters, and exhortations for the workforce, demanding Zero Defects and new levels of productivity, without providing methods. Such exhortations only create adversarial relationships; the bulk of the causes of low quality and low productivity belong to the system, and thus lie beyond the power of the workforce.

\section{(11) Eliminate Arbitrary Numerical Targets}

Eliminate work standards that prescribe quotas for the work-force and numerical goals for people in management. Substitute aids and helpful leadership for continual improvement of quality and productivity.

(12) Permit Pride of Workmanship

Remove the barriers that rob hourly workers, and people in management, of their right to pride of workmanship. This implies inter alia. abolition of the annual merit rating (appraisal of performance) and of Management by Objective. Again, the responsibility of managers, supervisors, foremen must be changed from sheer numbers to quality.

\section{(13) Encourage Education}

Institute a vigorous programme of education, and encourage selfimprovement for everyone. What an organisation needs is not just good people; it needs people that are improving with educition. Advances in Competitive position will have their roots in knowledge. 
(14) Top Management Commitment and Action

Clearly define top management's permanent commitment to ever improving quality and productivity, and their obligation to implement all the principles. Indeed, it is not enough that top management commit themselves for life to quality and productivity. They must know what it is that they are committed to that is, what they must do. Create a structure in top management that will push every day on the preceding 13 Points, and take action in order to accomplish the transformation. Support is not enough : action is required.

In conclusion only the fittest will survive. Those are the companies that adopt constancy of purpose for quality, productivity and service, and go about it with intelligence and perseverance have a chance to survive. These are the warning remarks as outlined by Dr. Deming in his book: Out of the crisis.

Deming has said that "if I had to reduce my message for the management to a few words, I'd say it all had to do with reducing variation".

\section{Mr. T (Taguchi) of the World of Quality}

When the Ina Tile company of Japan found that the uneven temperature profile of its kilns was causing unacceptable variation in tile size, it could have attempted to solve the problem with expensive modifications of the kilns. Instead it chose to make an inexpensve change in the settings of the tile design parameters to reduce sensitivity to temperature variation. Using a statistically planned experiment, the company found that increasing the lime content of the clay from $1 \%$ to $5 \%$ reduced the tile size variation by a factor of 10 (see Taguchi and Wu 1980).

The above example is an excellent illustration of the techniques introduced by Taguchi.

During the eighties a Japanese by the name of Genechi Taguchi employed some statistical methods to improve quality of various products by way of improving the processes. Taguchi's methods are some times controversial in the sense that improving quality leads to lower costs and improved productivity.

\subsection{Taguchi-techniques}

Following is a list of popular statistical techniques used by Professor Taguchi in improving and optimization procedures. Fractional factorial designs, orthogonal arrays, parameter designs, signal-to-noise ratios, loss functions, accumulation analysis. 
Taguchi has actually reused the Fisher's design of experiment methodology and Finney's fractional factorial designs and orthogonal arrays in interesting ways with remarkable benefits being derived.

\subsection{Some illustrative examples}

Now we will consider below an example where Taguchi's approach could be demonstrated in baking a cake robust to environmental conditions. (see George Box, Soren Bisgaard and Conrad Fung (1988) and G. Taguchi and Y. $\mathrm{Wu}$ (1980). This is a design known as parametric design according to him. Suppose we are interested in producing a cake mix that is robust to inaccurate setting of oven temperature (T) and baking time ( $t)$. In this example we may consider the following three design factors: the amount of flour(F), the amount of shortening (S) and the amount of egg powder (E), Now we are interested finding out if we can come out with a cake mix which is less sensitive to variability in the environmental factors namely the oven temperature and the baking time. the idea here is that our cake mix is such that a housewife need not get all the five factors described above dead right. Table below shows a design for such an experiment. In this table standard levels of the five factors are indicated by level zero. Each factor is tested by higher and lower levels indica ted by plus and minus signs respectively. In conducting this experiment number of cakes were made corresponding to different combinations of the factor levels.

A taste panel consisting of several members then evaluate the quality of cake by giving a score-hedonic index ranging from 1 to 7 . The average score is given in the table.

Table : Data from the cake - mix robustness experiment

\section{Design variables}

$\begin{array}{lllllllll} & & & \text { T } & \text { O } & - & + & - & + \\ \text { F } & \text { S } & \text { E } & \text { t } & \text { O } & - & - & + & + \\ \text { O } & \text { O } & \text { O } & & 6.7 & 3.4 & 5.4 & 4.1 & 3.8 \\ 1- & - & - & & 3.1 & 1.1 & 5.7 & 6.4 & 1.3 \\ 2+ & - & - & & 3.2 & 3.8 & 4.9 & 4.3 & 2.1 \\ 3- & + & - & & 5.3 & 3.7 & 5.1 & 6.7 & 2.9 \\ 4+ & + & + & & 4.1 & 4.5 & 6.4 & 5.8 & 5.2 \\ 5- & - & - & & 6.3 & 4.2 & 6.8 & 6.5 & 3.5 \\ 6+ & - & + & & 6.1 & 5.2 & 6.0 & 5.9 & 5.7 \\ 7- & + & + & & 3.0 & 3.1 & 6.3 & 6.4 & 3.0 \\ 8+ & + & + & & 4.5 & 3.9 & 5.5 & 5.0 & 5.4\end{array}$

Environmental variables 
F flour; S shortening ; E egg; T oven temperature; $t$ baking time

By looking at the above table closely it will be revealed that good tasting cakes can be made, even if you do not strictly adhere to the standards. E.g. run six or the two columns corresponding to $T \& t$ taking different signs produce good tasting cakes. As a matter of fact the best in this particular experiment is not obtained when standard is not followed for all the factors simultaneously, but the best value is 6.8 ; occuring when none of the standard values are used!

The following example demonstrates a similar design of experiment in the manufacture of a photocopying machine robust to various environmental and other factors. Recently Japan has developed a photocopying machine which could produce copies of almost any size at very high speed. 49 designed experiments involving 100 experimental runs were conducted in developing the machine. These experiments were aimed at making the machine robust to all the mishandling that might occur in practice and to the different environments it might encounter in various parts of the World. The manufacturer's objective was to make a machine that would produce good copies no matter whether there was high humidity, low humidity, high temperature, low temperature, thin paper, thick paper and so on. (See G.E.P. Box, R. Kackar, V. Nair, M Phadke, A. Shoemaker and C.F.J. Wu 1988).

Next we consider another application of Taguchi technique considered by $N$. Logothetis (1990). This is another very interesting application, to the area of designing electronic circuits. Generally speaking this is how the method works for any products of the type considered in Logothetis paper (see also Taguchi 1976, 1977; Bendell, Disney and, Pridmore 1989; Logothetis and Wynn, 1989). Supposing efficiert functioning of an electronic item e.g. T.V. set requires three independent and main electronic components. Each of these component will have its own tolerance interval ; the set will be functioning well no doubt if all the tolerances reside in the mid intervals. It is obvious that any departure from the middle, of any component may ask for a replacement of that particular component. But Taguchi says you need not do so. What he will do is to perform a sensible analysis to demonstrate that it is unwise to do so as it is an expensive job to replace so soon.

So, close monitoring of the components in the sense of keeping a close watch at the tolerance intervals is pretty economical indeed. Logothetis has devoted his paper completely to an actual case study of "optimization of a filter circuit used in Television transmitters". Of course you may not be able to forego the "no replacement policy" for all the components. But there are crucial components which need tightening of tolerances with the relaxing of non crucial ones giving rise to some savings which could be used for the tightening. Logothetis considers the problem in two stages : first optimum nominal settings of the components are determined so that the response is stable. 
i.e. there is low variability in the response; next it is decided on how much variability should be allowed in the components so that the robustness of the response could be further improved. At this stage additional cost might be avoided by relaxing the tolerances of the least crucial ones.

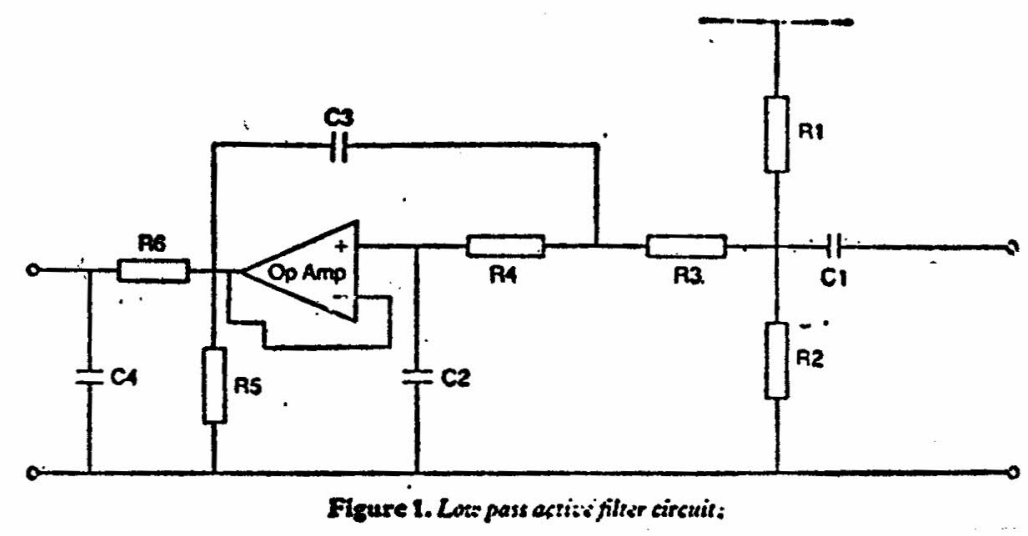

\section{The case study}

A RC 630 Law Pass Active Filter, part of the Television Transmit Circuit (Fig. 1) is studied.

The response $G(f)=10 \log \left(V(f)^{2}\right)$-for a given frequency $f$. The variance $V(f)$ could be calculated on the basis of the resistance of 6 resistors R1-R6 and the capacitance of 4 capacitors $\mathrm{C} 1-\mathrm{C} 4$ which comprise the circuit while the difference of $\mathrm{G}$ at $\mathrm{f}=2.55 \& 1 \mathrm{kHz}$ should lie between -2 and 1 decibels (dB) which is the same as $\mathrm{Y}=\mathrm{V}(2.55) / \mathrm{V}(1)$ lying between 0.7934 and 1.122 .

Three components were studied in the stage $1, \mathrm{R} 6, \mathrm{C} 2$ and $\mathrm{C} 3$ by varying at nominal levels (see Table 1). Past experience led to following assumptions: the three components were not interacting and the other components should be set at fixed nominal levels predetermined as optimal. The ten components were viewed both as controllable and as noise factors. 
Table 1. Nominal and tolerance levels

Circuit parameters as controllable factors

$\begin{array}{cc}\text { Tolerance } \\ \text { Circuit parameters } & \text { levels } \\ \text { as noise factors } & (\% \text { from nominal) }\end{array}$

Nominal levels

as noise factors ( $\%$ from nominal)

\begin{tabular}{|c|c|c|c|c|c|c|}
\hline & 1 & 2 & 3 & & 1 & 2 \\
\hline RI & & 27 & (fixed) & RI' & 2 & +2 \\
\hline $\mathbf{R} 2$ & & 27 & (fixed) & R2' & -2 & +2 \\
\hline R3 & & 22 & (fixed) & R3' & 2 & +2 \\
\hline R4 & & 22 & (fixed) & R4' & -2 & +2 \\
\hline R5 & & 56 & (fixed) & R5' & -2 & +2 \\
\hline R6 & 20 & 22 & 24 & R6' & -2 & +2 \\
\hline $\mathrm{Cl}$ & & 100 & (fixed) & $\mathrm{Cl}^{\prime}$ & -10 & +10 \\
\hline C2 & 0.82 & 1 & 1.2 & C2' & -5 & +5 \\
\hline C3 & 6.8 & 8.2 & 10 & C3' & -5 & +5 \\
\hline C4 & & 4.7 & (fixed) & C4' & -5 & +5 \\
\hline
\end{tabular}

\section{Experimental Design}

This is shown in Fig. 2 consisting of both an inner array and an outer array. The parameters when viewed as controllable factors are assigned to the "inner array" while when viewed as noise factors to the "outer array" For this kind of arrays Orthogonal Arrays (OA) were used as recommended by Taguchi. Such arrays allow the factors to have a different number of settings (levels) and also have the pairwise balancing property : every level of a factor occurs with every level of all other factors the same number of times. Fractional orthogonal arrays minimize the number of trial runs while keeping the pairwise balancing property (Taguchi, 1976, 1977). $\mathrm{OA}_{9}\left(3^{4}\right)$ chosen for inner array and the corresponding nominal values chosen are given in the Tables 2 and 3 respectively. All the other parameters namely R1-R5 \& $\mathrm{Cl}$, C4 are fixed as given in Table 1. Table 4 gives the layout for outer arrayan $0 A_{12}\left(2^{11}\right)$. 


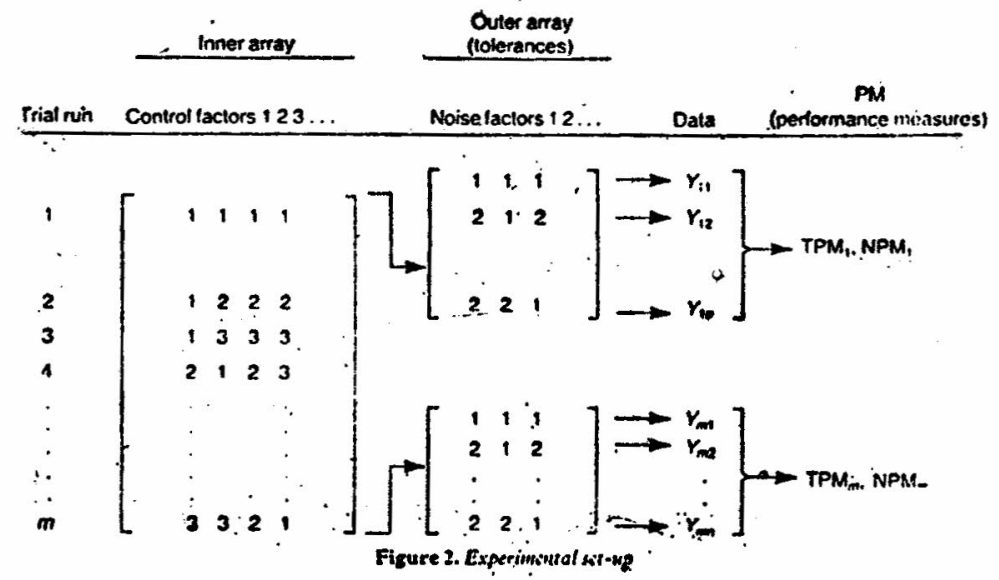

Table 2. $O A_{9}\left(3^{4}\right)$ for inner array

\begin{tabular}{lllll}
\hline \multicolumn{5}{c}{ Controllable factors } \\
\hline Trial run & C3 & R6 & C2 \\
\hline & & & & \\
\hline & 1 & 1 & 1 & 1 \\
2 & 1 & 2 & 2 & 2 \\
3 & 1 & 3 & 3 & 3 \\
4 & 2 & 1 & 2 & 3 \\
5 & 2 & 2 & 3 & 1 \\
6 & 2 & 3 & 1 & 2 \\
7 & 3 & 1 & 3 & 2 \\
8 & 3 & 2 & 1 & 3 \\
9 & 3 & 3 & 2 & 1 \\
\hline
\end{tabular}


Table 3. Inner array using nominal values

\begin{tabular}{llll}
\hline & \multicolumn{3}{c}{ Controllable factors } \\
\cline { 2 - 4 } Trial run & C3 & R6 & C2 \\
\hline & & & \\
1 & 6.8 & 20 & 0.82 \\
2 & 6.8 & 22 & 1.00 \\
3 & 6.8 & 24 & 1.20 \\
4 & 8.2 & 20 & 1.00 \\
5 & 8.2 & 22 & 1.20 \\
6 & 8.2 & 24 & 0.82 \\
7 & 10.0 & 20 & 1.20 \\
8 & 10.0 & 22 & 0.82 \\
9 & 10.0 & 24 & 1.00 \\
\hline
\end{tabular}

Table.4 $O A_{12}\left(2^{11}\right)$ for outer array

\begin{tabular}{llllllllllll}
\hline & & \multicolumn{1}{c}{ Noise Factors } \\
\cline { 2 - 9 } $\begin{array}{l}\text { Replication } \\
\text { run }\end{array}$ & R1' & R2' & R3' & R4' & R5' & R6' & C1' & C2' & C3' & C4' & C5' \\
\hline & & & & & & & & & & & \\
1 & 1 & 1 & 1 & 1 & 1 & 1 & 1 & 1 & 1 & 1 & 1 \\
2 & 1 & 1 & 1 & 1 & 1 & 2 & 2 & 2 & 2 & 2 & 2 \\
3 & 1 & 1 & 2 & 2 & 2 & 1 & 1 & 1 & 2 & 2 & 2 \\
4 & 1 & 2 & 1 & 2 & 2 & 1 & 2 & 2 & 1 & 1 & 2 \\
5 & 1 & 2 & 2 & 1 & 2 & 2 & 1 & 2 & 1 & 2 & 1 \\
6 & 1 & 2 & 2 & 2 & 1 & 2 & 2 & 1 & 2 & 1 & 1 \\
7 & 2 & 1 & 2 & 2 & 1 & 1 & 2 & 2 & 1 & 2 & 1 \\
8 & 2 & 1 & 2 & 1 & 2 & 2 & 2 & 1 & 1 & 1 & 2 \\
9 & 2 & 1 & 1 & 2 & 2 & 2 & 1 & 2 & 2 & 1 & 1 \\
10 & 2 & 2 & 2 & 1 & 1 & 1 & 1 & 2 & 2 & 1 & 2 \\
11 & 2 & 2 & 1 & 2 & 1 & 2 & 1 & 1 & 1 & 2 & 2 \\
12 & 2 & 2 & 1 & 1 & 2 & 1 & 2 & 1 & 2 & 2 & 1 \\
& & & & & & & & & & & \\
\hline
\end{tabular}


Fifty Years of Quality Technology

Table 5. Outer array for trial 1 of inner array

\begin{tabular}{|c|c|c|c|c|c|c|c|c|c|c|c|}
\hline \multirow{2}{*}{$\begin{array}{l}\text { Replication } \\
\text { run }\end{array}$} & \multicolumn{10}{|c|}{ Noise Factors } & \multirow[b]{2}{*}{ Data(y) } \\
\hline & $\mathbf{R} \mathbf{l}^{\prime}$ & R2' & R3' & R4' & R5' & R6' & $\mathrm{Cl}^{\prime}$ & $\mathrm{C} 2^{\prime}$ & C3' & C4' & \\
\hline $\begin{array}{r}1 \\
2 \\
3 \\
4 \\
5 \\
6 \\
7 \\
8 \\
9 \\
10 \\
11 \\
12\end{array}$ & $\begin{array}{l}26.46 \\
26.46 \\
26.46 \\
26.46 \\
26.46 \\
26.46 \\
27.54 \\
27.54 \\
27.54 \\
27.54 \\
27.54 \\
27.54\end{array}$ & $\begin{array}{l}26.46 \\
26.46 \\
26.46 \\
27.54 \\
27.54 \\
27.54 \\
26.46 \\
26.46 \\
26.46 \\
27.54 \\
27.54 \\
27.54\end{array}$ & $\begin{array}{l}21.56 \\
21.56 \\
22.44 \\
21.56 \\
22.44 \\
22.44 \\
22.44 \\
22.44 \\
21.56 \\
22.44 \\
21.56 \\
21.56\end{array}$ & $\begin{array}{l}21.56 \\
21.56 \\
22.44 \\
22.44 \\
21.56 \\
22.44 \\
22.44 \\
21.56 \\
22.44 \\
21.56 \\
22.44 \\
21.56\end{array}$ & $\begin{array}{l}54.88 \\
54.88 \\
57.12 \\
57.12 \\
57.12 \\
54.88 \\
54.88 \\
57.12 \\
57.12 \\
54.88 \\
54.88 \\
57.12\end{array}$ & $\begin{array}{l}19.6 \\
20.4 \\
19.6 \\
19.6 \\
20.4 \\
20.4 \\
19.6 \\
20.4 \\
20.4 \\
19.6 \\
20.4 \\
19.6\end{array}$ & $\begin{array}{r}90 \\
110 \\
90 \\
110 \\
50 \\
110 \\
110 \\
110 \\
90 \\
90 \\
90 \\
110\end{array}$ & $\begin{array}{l}0.78 \\
0.86 \\
0.78 \\
0.86 \\
0.86 \\
0.78 \\
0.86 \\
0.78 \\
0.86 \\
0.86 \\
0.78 \\
0.78\end{array}$ & $\begin{array}{l}6.46 \\
7.14 \\
7.14 \\
6.46 \\
6.46 \\
7.14 \\
6.46 \\
6.46 \\
7.14 \\
7.14 \\
6.46 \\
7.14\end{array}$ & $\begin{array}{l}4.46 \\
4.94 \\
4.94 \\
4.46 \\
4.94 \\
4.46 \\
4.94 \\
4.46 \\
4.46 \\
4.46 \\
4.94 \\
4.94\end{array}$ & $\begin{array}{l}0.9174 \\
0.8706 \\
0.9177 \\
0.8945 \\
0.8413 \\
0.9444 \\
0.8554 \\
0.9071 \\
0.9030 \\
0.9193 \\
0.8663 \\
0.9157\end{array}$ \\
\hline
\end{tabular}

Table 6. Outer array for trial 9 of inner array

\begin{tabular}{|c|c|c|c|c|c|c|c|c|c|c|c|}
\hline \multirow{2}{*}{$\begin{array}{l}\text { Replication } \\
\text { run }\end{array}$} & \multicolumn{9}{|c|}{ Noise Factors } & \multirow[b]{2}{*}{ C4' } & \multirow[b]{2}{*}{ Data(y) } \\
\hline & R1' & R2' & R3' & R4' & R5' & R6' & C1' & C2' & C3' & & \\
\hline $\begin{array}{r}1 \\
2 \\
3 \\
4 \\
5 \\
6 \\
7 \\
8 \\
9 \\
10 \\
11 \\
12\end{array}$ & $\begin{array}{l}26.46 \\
26.46 \\
26.46 \\
24.66 \\
26.46 \\
25.46 \\
27.54 \\
27.54 \\
27.54 \\
27.54 \\
27.54 \\
27.54\end{array}$ & $\begin{array}{l}26.46 \\
26.46 \\
26.46 \\
27.54 \\
27.54 \\
27.54 \\
26.46 \\
26.46 \\
26.46 \\
27.54 \\
27.54 \\
27.54\end{array}$ & $\begin{array}{l}21.56 \\
21.56 \\
22.44 \\
21.56 \\
22.44 \\
22.44 \\
22.44 \\
22.44 \\
21.56 \\
22.44 \\
21.56 \\
21.56\end{array}$ & $\begin{array}{l}21.56 \\
21.56 \\
22.44 \\
22.44 \\
21.56 \\
22.44 \\
22.44 \\
21.56 \\
22.44 \\
21.56 \\
22.44 \\
21.56\end{array}$ & $\begin{array}{l}54.88 \\
54.88 \\
57.12 \\
57.12 \\
57.12 \\
54.88 \\
54.88 \\
57.12 \\
57.12 \\
54.88 \\
54.88 \\
57.12\end{array}$ & $\begin{array}{l}23.52 \\
24.48 \\
23.52 \\
23.52 \\
24.48 \\
24.48 \\
23.52 \\
24.48 \\
24.48 \\
23.52 \\
24.48 \\
23.52\end{array}$ & $\begin{array}{r}90 \\
110 \\
90 \\
110 \\
90 \\
110 \\
110 \\
110 \\
90 \\
90 \\
90 \\
110\end{array}$ & $\begin{array}{l}0.95 \\
1.05 \\
0.95 \\
1.05 \\
1.05 \\
0.95 \\
1.05 \\
0.95 \\
1.05 \\
1.05 \\
0.95 \\
0.95\end{array}$ & $\begin{array}{r}9.5 \\
10.5 \\
10.5 \\
9.5 \\
9.5 \\
10.5 \\
5.5 \\
9.5 \\
10.5 \\
10.5 \\
9.5 \\
10.5\end{array}$ & $\begin{array}{l}4.46 \\
4.94 \\
4.94 \\
4.46 \\
4.94 \\
4.46 \\
4.94 \\
4.46 \\
4.46 \\
4.46 \\
4.94 \\
4.94\end{array}$ & $\begin{array}{l}0.7943 \\
0.6130 \\
0.6599 \\
0.6717 \\
0.6315 \\
0.6798 \\
0.6165 \\
0.7588 \\
0.6073 \\
0.6186 \\
0.7224 \\
0.7248\end{array}$ \\
\hline
\end{tabular}

Table 7. Trial means, standard deviations and NPMs for $Y$

\begin{tabular}{lccc}
\hline & \multicolumn{2}{c}{ Sample mean } & Sample std dev. \\
Trial run & $\overline{\mathbf{Y}}$ & $\mathrm{S}$ & $\mathrm{NPM}=-10 \log _{10}\left(\mathrm{~S}^{2}\right)$ \\
\hline 1 & 0.8960 & 0.03097 & 30.18 \\
2 & 0.7725 & 0.03445 & 29.26 \\
3 & 0.6348 & 0.03774 & 28.46 \\
4 & 0.7970 & 0.04935 & 26.13 \\
5 & 0.6172 & 0.04945 & 26.12 \\
6 & 0.8731 & 0.03502 & 29.11 \\
7 & 0.5549 & 0.05862 & 24.64 \\
8 & 0.9059 & 0.05754 & 24.80 \\
9 & 0.6749 & 0.06264 & 24.06 \\
\hline
\end{tabular}


Table 8. ANOVA for $Y$ at optimal setting

\begin{tabular}{lllc}
\hline Component & df & \multicolumn{1}{c}{ SS } & $\begin{array}{c}\text { Contribution ratio } \\
(\%)\end{array}$ \\
\hline R1 & & & \\
R2 & 1 & 0.0000304 & 0.286 \\
R3 & 1 & 0.00000884 & 0.08 \\
R4 & 1 & 0.00002611 & 0.245 \\
R5 & 1 & 0.00000817 & 0.075 \\
R6 & 1 & 0.0000029 & 0.025 \\
C1 & 1 & 0.0006351 & 0.060 \\
C2 & 1 & 0.0000429 & 0.405 \\
C3 & 1 & 0.0028367 & 26.9 \\
C4 & 1 & 0.0029673 & 28.14 \\
Residnal & 1 & 0.0039858 & 37.8 \\
& 1 & 0.00000023 & 5.98 \\
& & & 100.00 \\
\hline
\end{tabular}

Tables 5 and 6 show the outer array respectively for the 1st and 9th trial run of the inner array, using the actual tolerance levels. Note that there are only 12 tolerance level combinations (replication runs) out of $2^{10}=1024$ possible.

Results.-The 12 replication runs (from the outer array) at each of the nine trial runs (of the inner array) provided the data values of $Y$, for the calculation of a measure reflecting the mean response (Target Performance MeasureTPM) and a measure reflecting the variability in the response (Noise Performance Measure-NPM) at each trial run. Tables 5 and 6 show the Y data for the runs 1 and 9 respectively. The sample mean $Y$ and sample standard deviation $S$ for each of the nine trial runs were calculated, and these are shown in Table 7.

Analysis.-Followng the techniques described by Logothetis, 1988, the appropriate TPM and NPM were determined to be TPM $=Y$ and NPM $=-10 \log _{10}\left(\mathrm{~S}^{2}\right)$. The values of NPM for the nine trial runs are also shown in Table 7. An ANOVA for the NPM has shown that C3 significantly affects the NPM and therefore the variability in the response Y. So C3 can be considered as a variability control factor with optimal level 1 ; this is the level with maximum NPM, i.e. minimum value of $\mathrm{S}$.

An ANOVA for TPM showed C2 to be highly singificant. Since C2 does not affect the variability, it can be considered as a Target-control factor and can be manipulated to bring the mean response of $Y$ on target, optimum being the level 1. The factor R6 does not affect either TPM or NPM. 
Confirmaton Thus it is seen that the Level 1 is optimal for both $\mathrm{C} 2$ and C3. For R6, Level 1 was also chosen.

Logothetis further discusses how a futher improvement could be made if the response variability at an optimal setting so determined is still unacceptable, by a rational reduction of certain tolerances.

\subsection{Signal to Noise ratio}

Next we will consider another of Taguchi's most celebrated, popular and controversial as well technique, the S-N ratio or the Signal to Noise ratio as considered by Ramon V. Leon, Anne C. Shoemaker, and Raghu N. Kacker (1987), whom we may refer to as 'LSK' later on in this paper. Basically 'LSK' show in their paper that it is only in certain situations where a particular model for the response function is applicable that we may use the S-N ratio. And in other situations we are not permitted do so. As a matter of fact the trio suggest a new criterion a Quantity they call a PerMIA (Performance Measures Independent of Adjustment). This PerMIA may sometimes be the variance and it is the S-N ratio according to Taguchi but they are all special cases of the general notion of the PerMIA defined by Leon, Shoemaker and Kacker.

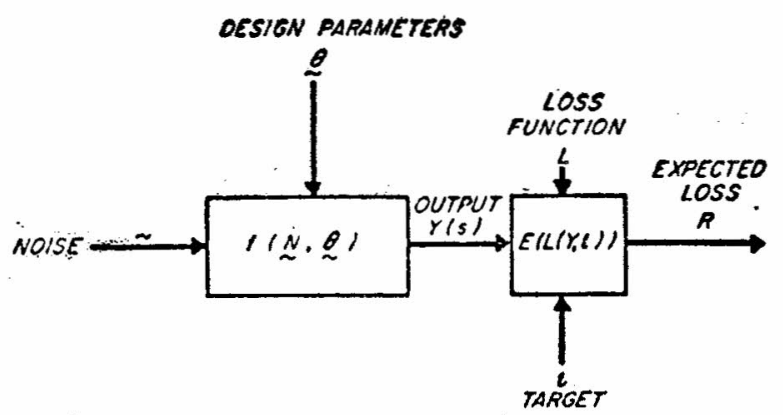

Figure 3. A Block Diagram Representation of a Simple Parameter-Design Problem. The output $Y$ is determined by the noise $N$ through the transfer function $f$. The transfer function depends on the design parameters 0 . Loss is incurred if the output is not equal to the target t.

Fig. 3 represents the diagram for a typical parameter design problem. Supposing $\mathrm{Y}$ is the charateristic output produced as a result of the design parameters $d, a$ and noise $N$. The output is determined by the transfer function $f(d, a, N)$. Since the noise is random $Y$ will be random as well. Departure from target $t$ will cause quadratic loss, $L(Y, t)=K(Y-t)^{2}$ and the average Loss is given by, $R(d, a)=E ~ L ~(Y, t)$. Taguchi calls this problem the static parameter design problem, because the target is fixed. In order to solve this problem Taguchi proceeds as follows (see Phadke 1982). 
Step 1 : Find the setting $\mathrm{d}=\mathrm{d}^{*}$ that maximizes the $\mathrm{SN}$ ratio.

Step 2 : Adjust a to $\mathrm{a}^{*}$ while $\mathrm{d}$ is fixed at $\mathrm{d}^{*}$

The division of design parameters into two groups is motivated by the idea that the parameters a are fine tuning adjustments that can be optimized after the main design parameters $d$ are fixed. Taguchi claimed that this two step approach has the advantage that, once a design $\left(\mathrm{d}^{*}, \mathrm{a}^{*}\right)$ is established, certain changes to product or process requirementsc an be accommodated by changing only the setting of the design parameter, a. The initial setting of $d=d^{*}$ remains optimal. For instance in the Ina Tile example mentioned earlier, the formulation could be chosen to minimize an $\mathrm{SN}$ ratio measurement of tile size variation, and then the tile mold size could be used to adjust the average tile size to target.

In this section we will discuss the LSK's proof of the compatibility of the SN ratio and using of the loss function.

For the said model of the response variable i.e.

$$
\mathrm{Y}=\mu(\mathrm{d}, \mathrm{a}) \mathrm{E}(\mathrm{N}, \mathrm{d})
$$

where $E E(N, d)=1$ so that $E(Y)=\mu(d, a)$.

We may obtain $R(d, a)=E(L)$ as,

$$
\mathrm{R}(\mathrm{d}, \mathrm{a})=\mu^{2}(\mathrm{~d}, \mathrm{a}) \sigma^{2}(\mathrm{~d})+(\mu(\mathrm{d}, \mathrm{a})-\mathrm{t})^{2}
$$

where $\sigma^{2}(d)=\operatorname{var}(E(N, d)$, and $K$ has been chosen to be one.

Then equatng the derivative of $\mathrm{R}$ with respect to a to zero gives,

$$
\begin{aligned}
& \mu\left(\mathrm{d}, \mathrm{a}^{*}(\mathrm{~d})\right)=\mathrm{t} /\left(1+o^{2}(\mathrm{~d})\right) \text {, where } \mathrm{a}^{*}(\mathrm{~d}) \text { is defined by } \mathrm{R}\left(\mathrm{d}, \mathrm{a}^{*}(\mathrm{~d})\right)= \\
& \min _{\mathrm{a}} \mathrm{R}(\mathrm{d}, \mathrm{a}) .
\end{aligned}
$$

Substituting this in $\mathrm{R}$ produces,

$$
\begin{aligned}
& \mathrm{P}(\mathrm{d})=\min _{\mathrm{a}} \mathrm{R}(\mathrm{d}, \mathrm{a})=\mathrm{t}^{2} \sigma^{2}(\mathrm{~d}) /\left(1+\sigma^{2}(\mathrm{~d})\right) \\
& \text { But } \mathrm{SN}=10 \log _{\mathrm{i} 0}\left(\mathrm{E}^{2} \mathrm{Y} / \text { var } \mathrm{Y}\right) \\
& =-10 \log \sigma^{2}(\mathrm{~d})
\end{aligned}
$$

and $P(d)$ increases with $\sigma^{2}(d)$.

Hence we can say that the minimization of the risk function $R$, is equivalent to the following two-step procedure. 
Step 1 : Find $\mathrm{d}$ that maximizes the $\mathrm{SN}$ ratio,

$$
\mathrm{SN}=10 \log _{10}\left(\mathrm{E}^{2} \mathrm{Y} / \mathrm{var} \mathrm{Y}\right) .
$$

Step $2:$ Find $\mathrm{a}^{*}$ such that $\mu\left(\mathrm{d}^{*}, \mathrm{a}^{*}\right)=\mathrm{t} /\left(1+\sigma^{2}\left(\mathrm{~d}^{*}\right)\right)$.

Thus it follows that with the muttiplicative model for the response $Y$ the use of the SN ratio leads to the minimization of the quadratic loss.

It is worthwhile noting that if the model is replaced by $Y=\mu+E$, with $\mathrm{E}(\mathrm{E})=\mathrm{O}$ then varY should be used instead of $\mathrm{SN}$ ratio.

LSK next consider a more general model given diagrammatically by Fig. 4 below.

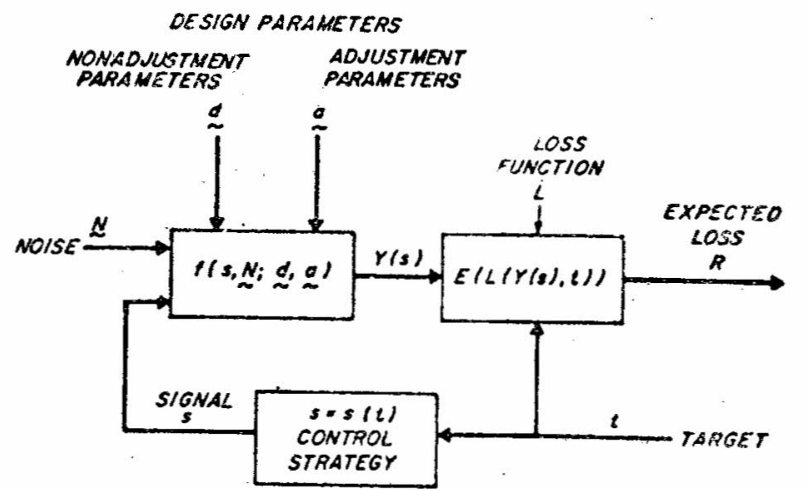

Figure 4 Pararneter Design of a Control Problem. The input signal is determined by the control strategy $s(t)$ and the intend-." ed target $t$. The object of the parameter design is to find the setting of the design parameters $(d, a)$ that minimizes expected loss $R(d, a)$. A more goneral objective of the parameter-design problem would be to find the minimum expected loss not only over the design parameter settings, but also over the permissible control strategies.

In this case, for a given setting of the design parameters $d$ and a, the output $\mathrm{Y}$ is determined by an input signal $\mathrm{s}$ and by noise $\mathrm{N}$. Loss is incurred if the out put is different from a target that may depend on the signal. As before, the goal of parameter design is to choose the optimal setting the same way i.e., such that, $R(d, a)=E_{S} E_{N}(L(Y, t(s)) d, a)$ is minimized where the distribution of the signal, $s$, reflects the relative frequency of its different values. This kind of system is a dynamic one., for the output and the target depend on a signal that is not fixed by the designer. For example, a measuring instrument such as a bathrocm scale is a dyanamic system, because its output, a weight reading, depends on the input signal, the actual weight of the person standing on the scale. The weight is also affected by noise factors such as temperature. 
The block diagram in Fig. 4 does not include every parameter design problem. For example, there may not be a signal, as we saw in the static problem earlier. However in the control problem considered in the next section the signal is determined by the target rather than vice versa. (see Fig. 5) This block diagram appropriately represents most of the parameter-design problems.

We saw that under the static parameter design problems $\mathrm{P}(\mathrm{d})$ is equivalent to Taguchi's SN ratio. However under other models and other loss functions although the same two-step procedure is applicable $P(d)$ is not equivalent to the SN ratio of Taguchi.

\subsection{Some Examples on Dyanamic Model}

LSK consider two more examples called by Taguchi and Phadke (1984) as continuous dynamic problems because the input and the output are continuous variables. Taguchi $(1976,1977)$ suggested a single SN ratio for all such problems. In order to check Taguchi's credibility LSK starts with the following formula for Y.

$$
\mathrm{Y}=\alpha+\beta^{1} \mathrm{~s}+\epsilon^{1}
$$

where $s$ is a continuous signal controlling a continuous output $Y$, and $\epsilon^{1}$ is a deviation from linearity . LSK report that Taguchi uses,

$$
\mathrm{SN}=\log _{10}\left(\beta^{2} / \operatorname{var}\left(\epsilon^{1}\right)\right)
$$

The $\mathrm{SN}$ ratio defined thus by the last two equations is independent of the form of the model of $Y$.

We will discuss below the two types of examples or models for $\mathrm{Y}$ considered by Leon, Shoemaker and Kacker.

\subsubsection{Measuring Instrument Example}

Suppose a manufacturer wants to design a measuring instrument and that the dial reading $\mathrm{Y}$ of the instrument satisfies

$$
Y=\alpha\left(\mathrm{d}, \mathrm{a}_{1}\right)+\beta\left(\mathrm{d}, \mathrm{a}_{2}\right)(\mathrm{r}(\mathrm{d}) \mathrm{s}+\epsilon(\mathrm{N}, \mathrm{d}))
$$

where $\operatorname{var}(\epsilon(N, D))=\sigma^{2}(d)$ and $E(\epsilon(N, d))=0$. Here $s$ is the true value of the measured quantity and $Y$ is the reading on the instrument's dial. To see the appropriateness of this model for a measuring instrument that can be calibrated, consider the case of spring scale such as a postal scale. The scale consists of two parts, the sensor which is the spring, and a dial, which translates compression $Z$, of the spring into weight reading. A model for the sensor part of the scale is $Z=r(d) s+\epsilon(N, d)$, where $s$ is the true weight of an object, $d$ is the design. 


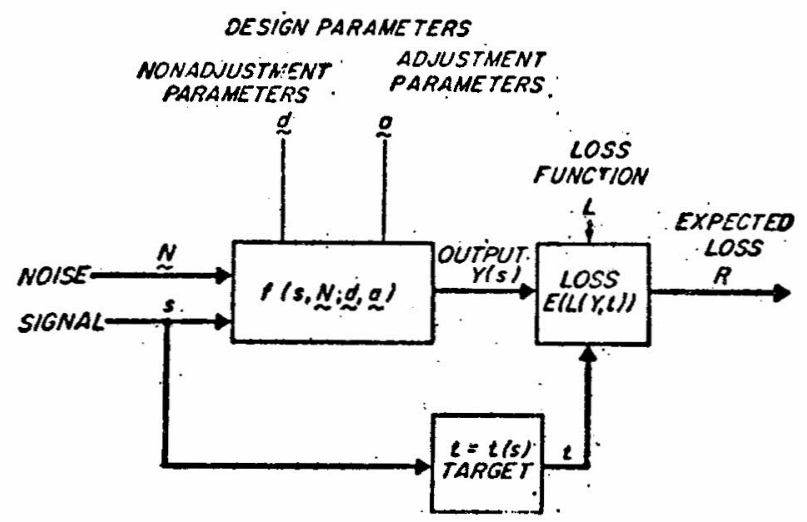

Figure of A Generic Parameter-Design Problem. The output $Y(s)$ is determined by an input signal $s$ and hoise $N$ : through a transfer function $f$. The transfer function depends on: the design parameters $d$ and a. Loss is incurred if the output is: not equal to the target value t (s)

parameters of the spring such as spring size and alloy and $\mathrm{N}$ is noises, such as imperfections in the spring, which affect compression. Since the location and the spacing of markings on the dial can be chosen by the designer, a model for the dial reading, $Y$ is $Y=\alpha\left(\mathrm{d}, \mathrm{a}_{1}\right)+\beta\left(\mathrm{d} \mathrm{a}_{2}\right) \mathrm{Z}$, where $\mathrm{a}_{1}$ and $\mathrm{a}_{2}$ are adjustments chosen by the designer. Substituting for $Z$ gives the complete formula (6) for $Y$.

For the general measuring instrument described by model (6), the desired value for the dial reading $Y$ is equal to the true value of s. Suppose the loss is measured by $(Y-s)^{2}$ then the objective of parameter design is to find the setting of $(d, a)$ that minimizes $E_{s} E_{n}\left((Y-s)^{2} l d, a\right)$.

In addition, suppose the designer requires that $d$ and a should be chosen so that $\mathrm{E}((Y / \mathrm{d}, \mathrm{a}, \mathrm{s})=\mathrm{s})$. that is design must give unbiassed estimate $\mathrm{s}$ for $Y$. Then to find the optimal setting, $\left(d^{*}, a^{*}\right)$, note that.

$$
\begin{aligned}
\min _{\mathrm{d}} \min _{\mathrm{a}} \mathrm{E}_{\mathrm{s}} \mathrm{E}_{\mathrm{n}}\left((Y-\mathrm{s})^{2} \mathrm{ld}, \mathrm{a}\right)= & \min _{\mathrm{d}} \min _{\mathrm{a}}\left(\beta^{2}\left(\mathrm{~d}, \mathrm{a}_{2}\right) \operatorname{var}_{\mathrm{n}}(\epsilon(\mathrm{N}, \mathrm{d})\right. \\
+ & \left.\mathrm{E}_{\mathrm{s}}\left(\alpha\left(\mathrm{d}, \mathrm{a}_{1}\right)+\beta\left(\mathrm{d}, \mathrm{a}_{2}\right) \mathrm{r}(\mathrm{d}) \mathrm{s}-\mathrm{s}\right)^{2}\right) \\
& =\min _{\mathrm{a}}\left[\operatorname{var}_{\mathrm{n}}(\epsilon(\mathrm{N}, \mathrm{d})) / \mathrm{r}^{2}(\mathrm{~d})\right]
\end{aligned}
$$

The last of the preceding equalities holds because $a_{1}{ }^{*}(d)$ and $a_{2}{ }^{*}(d)$ must satisfy $\alpha\left(\mathrm{d}, \mathrm{a}_{1}{ }^{*}(\mathrm{~d})\right)=0$ and $\beta\left(\mathrm{d}, \mathrm{a}_{2}{ }^{*}\right.$ (d)) $\mathrm{r}(\mathrm{d})=1$ each for under unbiasedness constraint. The function $\operatorname{var}(\epsilon(\mathrm{N}, \mathrm{d})) / \mathrm{r}(\mathrm{d})$ is a PerMIA, because it does not depend on the adjustment parameters, $a_{1}$ and $a_{2}$. The PerMIA measures performance of the measuring instrument as it would be after proper calibration. 


\subsubsection{Control System Ex. Designing a Truck-steering Mechanism}

We will show in this example how a PerMIA is derived in a realistic design problem, the design of a truck-steering mechanism. This example, a modification of one given by Taguchi and $\mathrm{Wu}(1980)$ also illustrates how adjustment parameters arise in practice. The truck driver chooses the steering angle $s$ to make a turn of radius t. (Turning angle may seem a more natural measure of the truck's response to a certain, steering angle, but turning radius is much easier to measure.) The chosen angle is determined by the driver's control strategy. In designing the truck-steering mechanism, the engineer's objective is to minimize the expected loss caused by deviation of the truck's actual turning radius from the driver's intended turning radius. This deviation is caused by noise such as road condition, load position, and tyre pressure. [Driving speed is another noise that has a profound effect on how the truck responds to a given steering angle. For simplicity we assume that speed is constant. See Taguchi and $\mathrm{Wu}(1980)$ for a solution that includes speed as a nosie factor].

As mentioned previously, one way to make the steering mechanism insensitive to noise is to weld the steering mechanism so that the truck always goes straight. Of course, this would not do, because, in addition to minimizing sensitivity to noise, the design must allow the driver to make any needed turn using a comfortable steering angle. In particular, since the size of the steering angle is inversely related to the force required to turn the steering whcel, comfortable steering angles are neither too large nor too small-small angles require too much exertion; large angles require too many turns of the steering wheel. Suppose the engineer expects that the driver will need to make turns between $t_{L}$ meters and $t_{H}$ meters and the force required to turn the steering wheel, comfortable steering angles are neither too large nor too small turns of the steering wheel. Suppose the engineer expects that the driver will need to make turns between $t_{L}$ meters and $t_{H}$ meters and comfortable steering angles for making these turns are between $s_{L}$ and $s_{H}$ degrees.

As before the block diagram in Fig. 5 summarizes the problem from the point of view of parameter design. The truck driver who intends to make a turn of radius $t$ chooses a steering angle $s$ using his control strategy $s(t)$. The truck responds with a turn of radius $\mathrm{Y}$, which depends on the steering angles the noise conditions $\mathrm{N}$, and the design of the steering mechanism.

In this example hardness of front springs (A), type of steering geometry (B) and gear ratio(G) were used as design parameters. LSK then show that a PerMIA will not exist if the usual quadratic function for $\mathrm{Y}$ is assumed, transfer function used being, 
$\mathrm{Y}=(\mathrm{Gs})^{-8}{ }^{(\mathrm{N}, \mathrm{a}, \mathrm{b})}$. However a PerMIA, $\sigma^{2}(\mathrm{~A}, \mathrm{~B})$ is found to exist when $\mathrm{L}(\mathrm{Y}, \mathrm{t})$ is modified to be $(\log -\mathrm{tog} t)^{2}$.

\subsection{Alternatives to Taguchi's SN ratio}

George Box (1988) introduces different versions of the signal to noise ratio and the PerMIA in this paper when the objective is to make the response (i) as large as possible and (ii) as small as possible.

Following three $\mathrm{SN}$ ratios are defined by Box.

(i) $\left\{\mathrm{SN}_{\mathrm{T}}\right\}=10 \log _{10}\left(\mathrm{y}^{2} / \mathrm{s}^{2}\right)$

with $\bar{y}=\Sigma y_{i} / n$ and $s^{2}=\Sigma\left(y_{i}-\bar{y}\right)^{2} /(n-1)$, is employed when the objective is closeness to target.

(ii) $\left\{\mathrm{SN}_{\mathrm{L}}\right\}=-10 \log _{10}\left[\Sigma \mathrm{y}_{\mathrm{i}}^{-2} / \mathrm{n}\right]$

is employed when the objective is to make the response as large as possible.

(iii) $\left\{\mathrm{SN}_{\mathrm{s}}\right\}=-10 \log _{10}\left[\Sigma \mathrm{y}_{1}^{2} / \mathrm{n}\right]$

is employed when the objective is to make the response as small as possible

In explaining the use of $\{\mathrm{SN}\}$, Phadke (1982) has said "why do we work in terms of $\mathrm{S} / \mathrm{N}$ ratio rather than the standard deviation? Frequently as the mean decreases the standard deviation also decreases and vice versa. In such cases, if we work in terms of the standard deviation, the optimization cannot be done in two steps i.e., we cannot minimize the standard deviation first and then bring the mean on target. (p. 13)"

Phadke later explained.....

Among many applications, Professor Taguchi has empirically found that the two stage optimization procedure involving the $\mathrm{S} / \mathrm{N}$ ratio indeed gives the parameter level combination where the standard deviation is minimum while keeping the mean on target. This implies that the engineering systems behave in such a way that the manipulative production factors can be divided into three categories :

(1) control factors, which affect process variability as measured by the $\mathrm{S} / \mathrm{N}$ ratio

(2) signal factors, which do not influence (or have negligible effect on) the $\mathrm{S} / \mathrm{N}$ ratio but have significant effect on the mean, and

(3) factors which do not affect the $S / N$ ratio or the process mean. 
Box proceeds as follows. Suppose that we wish to minimize the mean squared error (MSE) $M=E(y-T)^{2}$ of some quality characteristic y about a target $T$ with respect to design factors (variables) $x$. Equivalently this would minimize expected loss if an appropriate quadratic loss function is assumed. In general both $\mu=E(y)$ and $\sigma^{2}=E(y-\mu)^{2}$ will depend on $x$. and for fixed $x$ we may wirte,

$$
M(x)=E(y(x)-T)^{2}=\sigma^{2}(x)+(w(x)-T)^{2}
$$

A very general way to proceed would be to regard $M$ (or preferably its logarithm) as a response and to conduct designed experiments to find conditions $\mathrm{x}_{0}$, which gave a response close to the minimum (see, e.g., Box and Draper 1987; Box and Fung 1986; Box and Wilson 1951). Suppose that the system has certain special characteristics that can be used to simplify the problem. The general idea is to get rid of dispersion effects (see, e.g., Box and Meyer 1986b) that arise only because of dependence of $\sigma$ on $\mu$. Specifically Box assumes that that the standard deviation and the mean are linked in a manner such that a function $f(\mu(x))$ can be found for which $\sigma^{2}(x) /(f(\mu(x)))^{2}$ is a measure of dispersion $P\left(x_{1}\right)$, which is a function of only a subset $x_{1}$ of the design variabes $x=\left(x_{1}, x_{2}\right)$. Then $P\left(x_{1}\right)$ is independent of $\mu$, because for given $x_{1} \mu$ is a function of $x_{2}$ only. But $P$ is not a function of $x_{2}$, and consequently $P\left(x_{1} / \mu\right)=P\left(x_{1}\right)$. Equivalently if dispersion is measured in terms of $P\left(x_{1}\right)$, then only a subset of the design factors $x$ will have dispersion effects, $P\left(x_{1}\right)$ will be a PerMIA and $x_{2}$ will be a vector of adjustment factors that can be changed without changing dispersion.

On these assumptions

$M(x)=\{f[\mu(x)]\}^{2} P\left(x_{1}\right)+(\mu(x)-T)^{2}$

and for fixed $\mu, \mathrm{M}(\mathrm{x})$ is minimized with respect to $\mathrm{x}_{1}$ when $\mathrm{P}\left(\mathrm{x}_{1}\right)$ is minimized. Suppose now that $P\left(x_{1}\right)$ is uniquely minimized when $x_{1}=x_{10}$, an absolute minimum for $M(x)$ may be found if, by changing only $x_{2}, \mu$ can be adjusted to its minimizing value $\mu \mathrm{o}$ where

$$
\mu \mathrm{o}=\mathrm{T}-\mathrm{f}(\mu \mathrm{o}) \mathrm{f}^{1}(\mu \mathrm{o}) \mathrm{P} .
$$

By making the important assumption that a point $x_{1}=x_{10}$ exists that minimizes $M$ with respect to $\mu$ Box shows that $M$ could be minimized in two stages. He names the quantity $\mathrm{f}\left(\mu_{0}\right) \mathrm{f}^{1}\left(\mu_{0}\right) \mathrm{P}$ the aim-off-factor. For illusstrative purposes then he takes $\mathrm{f}(\mu)=\mu^{\alpha}$, then

$$
P=\sigma^{2} ! \mu^{2 \alpha}
$$




\subsection{Graphical, Illustrations}

In Fig.6, 6(a) shows the dependence of $x_{1}$ and $x_{2}$ on $\mu$ and $\sigma . F i g$ 6 (b) shows the contours of MSE, $M\left(x_{1}, x_{2}\right)$ for target $T=10$, showing a mininum point at $Q$. The diagrams for this example has been generated by taking PerMIA $\mathrm{P}=\left(\sigma / \mu^{2}\right)^{2}$, which we suppose is a function of $\mathrm{x}_{1}$ only as illustrated in Fig.6 (c). The supposition is, therefore that the uneecessary dispersion effects associated with $x_{1}$ in Fig.6(d) and 6(a) arise because the standard deviation is proportional not to the mean but to its square. Fig. 6(c) illustrates the situation where adjusting $x_{1}$ alone, $P$ can be brought to its minimizing value of $36 \times 10^{-6}$. The adjustment factor $x_{2}$ may now be manipulated to bring $U$ to the value

$$
\mu_{0}=\mathrm{T} /\left(1+2 \mathrm{P} \mu_{0}^{2}\right) \text {. }
$$

Box then explains how this value could be further improved. Fig.6(d) shows the contours of $\mu$ and of the SN ratio $(\mu / \sigma)^{2}$. Further the following valuable comments were made by him. Typically in this kind of experiments, wide ranges are allowed for factors $x$; hence for $y$ are also likely, implying some detectable dependence of $\sigma$ on $\mu$ as well, and for measurements having a natural origin at $O$ (such as height, weight, area, tensile strength, yield, absolute temperature, and reaction time) it is often true that the standard deviattion increases with the mean. In the absence of anything better, therefore, tacitly assuming a proportional increase a aconstant coefficient of variation-would make more sense than to assume no dependence (see in particular,Gaddum 1945)

\subsection{Relation between $\sigma_{\text {Iny }}$ and $\mathrm{C.V}$}

Box then discusses the transformation of $\mathrm{Y}, \log (\mathrm{Y})$ in particular. As observed by Johnson and Kotz (1970) it is well known that the coefficient of variation (C.V.), $\quad \mathrm{r}=\sigma / \mu$ is, almost proportional to the standard devia tion of In y. More specifically if after a $\log$ transformation $Y=\ln y$ has mean $\mu \mathrm{y}$ and constant variance $\sigma_{\mathrm{y}}^{2}$, then exactly if $\mathrm{Y}$ is normally distributed and approximately otherwise,

$\mu=\exp \left(\mu_{\mathrm{y}}+\sigma_{\mathrm{y}}^{2} / 2\right), \quad \sigma=\mu\left(\exp \left(\sigma^{2} \mathrm{y}\right)-1\right) \frac{1}{2}$

Following deductions follow from (12), S.D.of y, $\sigma$ is exactly proportional to its mean $\mu$ or their ratio, the coefficient of variation is indepedent of $\mu$ Also as sketched in Fig. 7, C.V. is a monotonic function of $\sigma y$. Thus Box concludes that the analysis in terms of $\mathrm{SN}$ ratio is essentially equivalent to

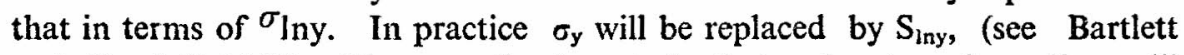
and Kendall 1946). Thus on the hypotesis that a $\log$ transformation will stabilize the variance we are led to an analysis of in $\mathbf{S}_{\mathrm{lny}}$. This is almost equivalent to (SNT), since

$$
\begin{aligned}
\left\{\mathrm{SN}_{\mathrm{T}}\right\} & =-10 \log (\mathrm{s} / \mathrm{y})^{2}=\text { const }-20 \log \mathrm{s}_{\text {loz }} \mathrm{y} \\
& =\text { const }- \text { const } \ln _{\text {lny }}
\end{aligned}
$$




\subsection{Conclusions}

Box has made the following conclusions with regard to data analytic approach and using of various SN ratio types.

The information in experimental data, both expected and unexpected, is best revealed by data analytic methods rather than in terms of portmanteau criteria decided in advance such as $\mathrm{SN}_{\mathrm{T}}, \mathrm{SN}_{\mathrm{S}}$, and $\mathrm{SN}_{\mathrm{L}}$. The analysis of experiments designed to discover how exprimental factors affect dispersion as well as location is greatly simplified if functional dependence of dispersion on location can be eliminated. For a given set of data, possibilities of doing this may be conveniently reviewed by considering an appropriate analysis over a range of transformations of the response, as in the lambda plot. In particular, such an analysis is helpful when designed experiments are run to find process conditions that achieve the smallest MSE about some target value. The $\left\{\mathrm{SN}_{\mathrm{T}}\right\}$ criterion would be appropriate in an endeavor of this kind only for the special case in which $\sigma$ is froportional to $\mu$, but it would usually be less efficient than an analysis of logy.

Statistics should be introduced to engineers as a means of catalyzing engineering and scientific reasoning by way of design and data analysis. Such an approach, emphasizing graphical methods with suitable computer programs, will result in greater creativity and, if taught in a wide enough scale, could markedly improve quality and productivity and our overall competitive position. 
Fifiy Years of Quality Technology
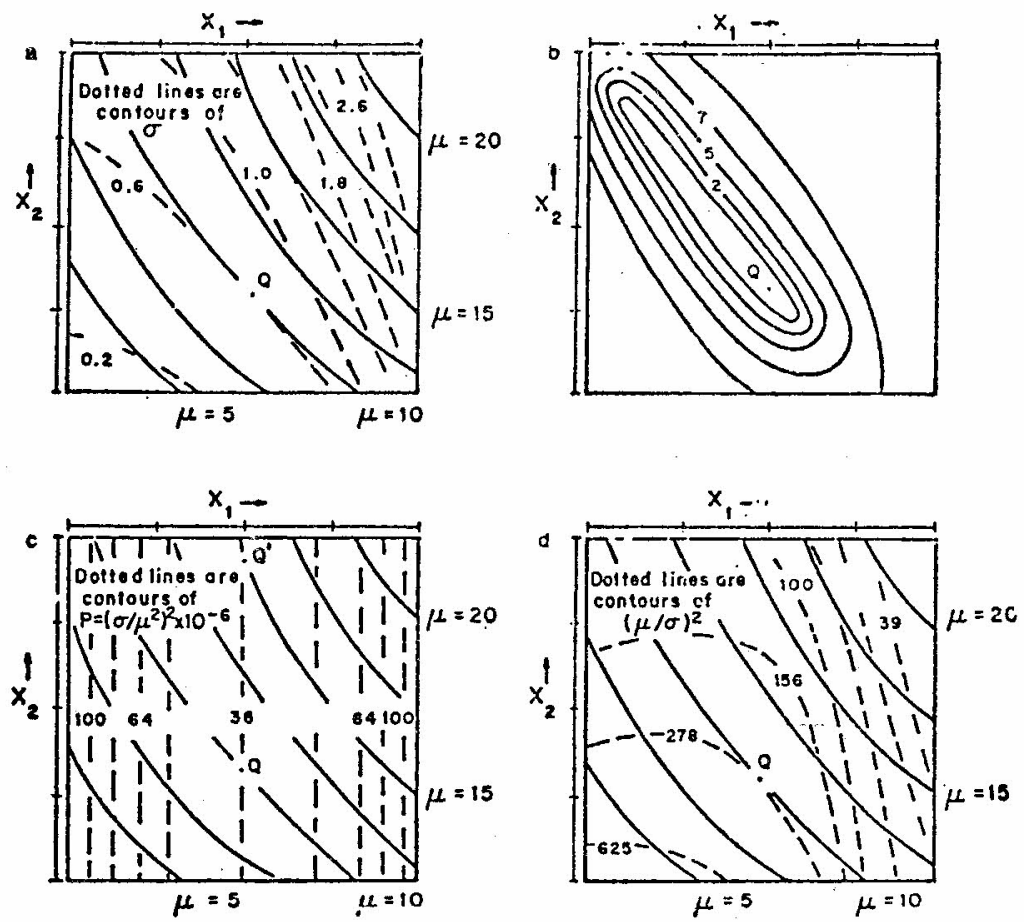

Figure 6. Simplification Induced Only by Employment of the Current perMIA of $\mu_{2}$ : (a) Contours of $\mu$ and $\sigma$ for Two Design Variables, $x_{1}$ and $\times_{2}$. (b) a Plot of Mean Squared Error for the Same Situation Showing a Minimum at Q : (c) Contours of $\mu$ and of the PerMIA $P=\left(\sigma / \mu^{2}\right)^{2}$ for the Same Situaticn (rote that $\times 2$ is now an adjustment factor); (d) Contours $\mu$ and of the Signal to Noi e Ratio $(\mu / \sigma)^{2}$.

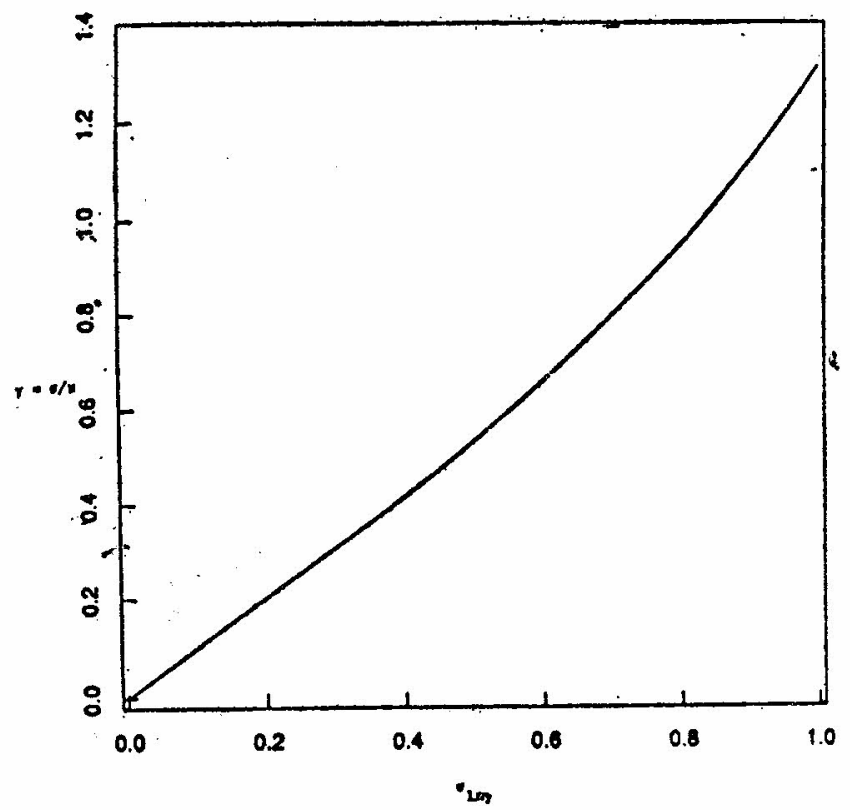

Figure 7. The Relation Between $\sigma$ in y and the Coefficient of Variation $\sigma / \mu$ When in $v_{i}$ i Normaly Distributed. 


\section{Bayesian Approach}

R. N. Curnow and R. A. Dayananda have attempted to use prior informa. tion in the parametric design problem and made a comparision with Taguchi and maximum likelihood estimate method. (The use of Prior and Experimental Information in Setting Process Control Variables, 1991).

\subsection{Loss and risk functions}

They considered a loss function of the form,

$$
y=-x^{2}
$$

where $y$ is the economic value of an industrially produced item depending on the measurable variable, $x$. The optimal value of $x$ is assumed known and set equal to zero, so is $\mathrm{y}$ at $\mathrm{x}=0$.

A choice of values for the parameters controlling the process, referred to as treatment, has to be made. For one set of parameter values, that is one treatment, the products of the process is assumed to have values of $x$ Normally distributed with unknown mean $\mu$ and unknown variance $\sigma^{2}$. The problem is to choose a treatment using prior and experimental information. The eobjective is to choose the treatment which maximizes the risk,

$$
\mathrm{E}(\mathrm{y})=-\mathrm{E}\left(\mathrm{x}^{2}\right)=-\left(\mu^{2}+\sigma^{2}\right)
$$

\subsection{Estimation of $\left(\mu^{2}+\sigma^{2}\right)$}

Assuming a Normal-Gamma prior for the joint distribution of $\left(\mu, \sigma^{2}\right)$ the following result was obtained by them.

$$
\mathrm{E}\left(\mu^{2}+\sigma^{2}\right)=\mu_{0}^{2}+\mathrm{V}_{0}\left(\mathrm{n}_{0}^{2}-1\right) /\left(\mathrm{n}_{0}\left(\mathrm{n}_{0}-5\right)\right)
$$

Where $\mu_{0}, \mathrm{~V}_{0}, \mathrm{n}_{0}$ are prior parameters.

The unbiassed maxinum likelihood estimate is,

$$
\operatorname{MLE}\left(\mu^{2}+\sigma^{2}\right)=\mathrm{x}^{-2}+(\mathrm{n}-1) \mathrm{s}^{2} / \mathrm{n}
$$

Under both the prior and experimental information,

$$
\begin{aligned}
& \mathrm{E}\left(\mu^{2}+\sigma^{2}\right)=\left\{\left(\mathrm{n}_{\overline{\mathrm{X}}}+\mathrm{n}_{6} \mu_{0}\right) /\left(\mathrm{n}+\mathrm{n}_{0}\right)\right\}^{2}+\left[\left(\mathrm{n}+\mathrm{n}_{0}+1\right) /\left\{\left(\mathrm{n}+\mathrm{n}_{0}\right) \quad\left(\mathrm{n}+\mathrm{n}_{0}-5\right)\right\}\right] \mathrm{X} \\
& \text { Where } \mathrm{X}=(\mathrm{n}-1) s^{2}+\left(\mathrm{n}_{0}-1\right) \mathrm{V}_{0}+\mathrm{nn}_{0}\left(\overline{\mathrm{X}}-\mu_{0}\right)^{2}\left(\mathrm{n}+\mathrm{n}_{0}\right)
\end{aligned}
$$




\subsection{Simulations}

Simulation was used to generate unknown parameters $\mu$ and $\sigma$ and the $\mathrm{x}$ 's for given $\mu$ and $\sigma$. The procedures given in Newman and Odell (1971) were used for this purpose.

\subsection{Five Procedures for Choosing the Best Treatment}

Four treatments were compared under five different methods. three are based directly on the values of the estimates of $\left(\mu^{2}+\sigma^{2}\right)$. The other two are based solely on the experimental information and hence on the M.L.E. One of the two is called "Taguchi related" and the other "Main Effects" method. In these two procedures the four treatments are assumed to form a $2^{2}$ factorial. The "Taguchi" method assumes that one factor, A say, affects only $\mu$ but the other factor $\mathrm{B}$, affects both $\mu$ and $\sigma$. The procedure first identifies the treatment with the lowest estimated standard deviation. Then a choice is made on the basis of the estimated $\left(\mu^{2}+\sigma^{2}\right)$ of the level for factor A holding fixed the level of factor $\mathbf{B}$.

In the main effects method the level of each factor is chosen separately as that which has the lowest value of the estimate of $\left(\mu^{2}+\sigma^{2}\right)$ when averaged over the levels of the other factor.

The following Table (Table 9) gives the values for $\mu_{0}, V_{0}$ that were chosen. The different levels of the factors $A$ and $B$ are denoted by the suffixes $O$ and 1 .

Table 9. Levels of $\mu_{0}$ and vo

$\begin{array}{lllccr}\text { Treatment : } & I\left(A_{0} B\right)_{0} & I I\left(A_{1} B_{0}\right) & I I I & \left(A_{0} B_{1}\right) & I V\left(A_{1} B_{1}\right) \\ \mu_{0} & : & 0.10 & 0.20 & 0.10 & 0.20 \\ v_{0} & : & 0.01 & 0.01 & 0.02 & 0.02\end{array}$

The three estimates of $\mu^{2}+\sigma^{2}$ together with the sample variance for each treatment combination (Table 10) for given $n=10, n_{0}=10$ are computed.

Table 10 Estimates of $\mu^{2}+\sigma^{2}$ and $s^{2}$

$\begin{array}{rlccc} & \text { Prior } & \text { mle } & \text { postr. } & s^{2} \\ \text { I }\left(\mathrm{A}_{0} \mathrm{~B}_{0}\right) & 0.0298 & 0.0328 & 0.0319 & 0.0161 \\ \text { II }\left(\mathrm{A}_{1} \mathrm{~B}_{0}\right) & 0.0598 & 0.0667 & 0.0621 & 0.0076 \\ \text { III }\left(\mathrm{A}_{0} \mathrm{~B}_{1}\right) & 0.0496 & 0.0206 & 0.0329 & 0.0125 \\ \text { IV }\left(\mathrm{A}_{1} \mathrm{~B}_{1}\right) & 0.0296 & 0.0342 & 0.0537 & 0.0125\end{array}$


Because they lead to the lowest estimates of $\mu^{2}+\sigma^{2}$, IV, III, and I would be the chosen treatments with judgements based on the prior information only, the experimental information only, and both combined respectively. It should be noted that using only the prior information, IV will always be chosen for a given set of values. To apply the "Taguchi related" method, the variance estimate $\mathrm{s}^{2}$ in last column would lead us to choose II. We then compare mle in I and II Min $(0.0328,0.0667)$ giving $I$ as the chosen treatment. Using Main effects method the average of mle corresponding to I, III is smaller than that corresponding to II, IV leading to the choice of Ao. Comparing averages of I,II and III,IV implics $\mathrm{B}_{1}$. Combining we obtain III $\left(\mathrm{A}_{0}, \mathrm{~B}_{1}\right)$ as the optimal treatment.

Table 11 gives the frequencies of the choices of the treatments I,II,III,IV under each procedure for a range of $n_{0}$ and $n$ together with the theoretical values of $\mu^{2}+\sigma^{2}$. At the foot of each Table the mean and standard deviation of the chosen values of $\left(\mu^{2}+\sigma^{2}\right)$ of one hundred replicates are also given. The theoretical values the means and standard deviations are given in parentheses. 
Table 11

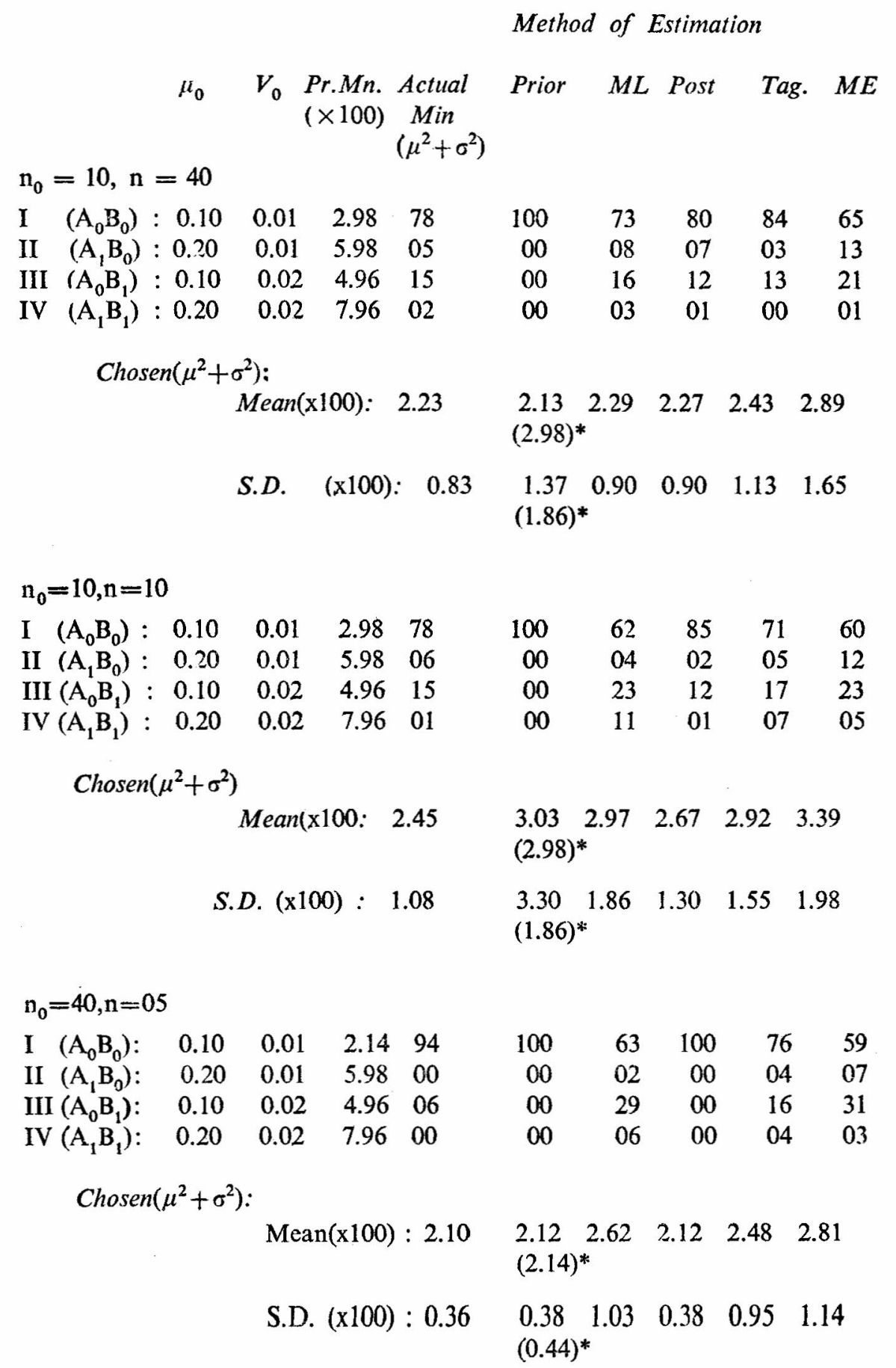




\section{References}

Soren Bisgaard, (Jan. 1990), Quality Engineering and Taguchi : Methods: A Perspective, Centre for Quality and Productivity Improvement, University of Wisconsin Madison.

Juran, J.M. and Gryna, F.M. Jr., (1970), Quality Planning and Analysis, New York: Mcgraw Hill.

Shewart, W.A. (1931), Economic Control of the Quality of Manufactured Product, New York: Van Nostrand Company.

Shewart, W.A. (1939), Statistical Method from the Vew Point of Quality Control, edited by W Edwards Deming Washington D.C.: Graduate School of the Department of Agri culture. Reprinted 1986 by Dover Publications Inc. with new foreword by W. Edwards Deming.

Deming. W.E. (1986), Out of the Crisic, Cambridge, MA:MIT Press.

Ishikawa, K. (1976), Guide to Quality Control, New York: Unpub.

Box, G.E.P., and Bisgaard, S. (1987), "The Scientific Context of Quality Improvement", Quality Progress, VoIXX, 6, 54-61.

Tippett, L.H.C. (1936), "Application of Statistical Methods to the Control of Quality in Industrial Preduction, Transactions of the Marchester Statistical Society.

Shewart, W.A. (1938), "Application of Statistical Method in Mass Production" in Proceeding of the Industrial Statitic Conference, New York: Pitman Publishing Corporation.

Simon, L.E. (1938), "A Method of Expressing Quality", in Proceeding of the Indutsrial Statistics Confercnce, New York: Pitman Publishing Corporation.

Simon, L.E. (1941), An Engineer's Manual of Statistical Methods, New York: John Wiley and Sons.

Wilks, S.S. (1938), "The Rise of Modern Statistical Science", in Prcceeding of the Industrial Statistics Conference, New York. Pitman Publisning Corporation.

Freeman, H.A. (1938), "Types of Stat stical Methods Used and Problems Handied in Indus trial Quality Control", in Proceeding of the Industrial Statistics Conference, New York. Pitman Publishing Corporation.

Tippett, L.H.C. (1938), "The Statistical Principle of Experimental Design, with particular reference to Experimentation in Textile Factories", in Proceeding of the Industrial Statistics Conference, New York. Pitman Publishing Corporation.

- Statistical Aspects of the Control of Quality in Textile Manufacture", in Proceeding of the Industrial Statistics Conference, New York: Pitman Publishing Corporation.

- (1950), Technological Applications of Statistics, New York: John Wiley and Sons.

Logothetis, N. (1990), Managing the Component-tolerances, Total Quality Management vol.1.,no.1.

Bendell, A., Disney, J. \& Pridmore, W.A. (Eds.) (1989), Taguchi Methods: Applications in World Industry (Springer-Verlag, IFS Publications)

Logothetis, N. \& Wynn, H.P. (1989) Quality Through Design: Experimental Design, Offline Quality Control and Taguchi's Contributions (Oxford, Clarendon Press, Oxford University Press).

Taguchi, G. (1976) 1977) Systems of Experimental Design, Vols. I (1976) and II (1977) with translation. (White Plaimns, New York: Unipub Kraus International Publications).

Daniel, C. (1962) Sequences of fractional replicates in the $2^{p-q}$ series, J. Am Statist., Assoc 57, 403.429 . 
Youden, W.J. (1961), 'Experimental Design and ASTM committees', Materiais Research and Standards, Reprinted in Precision Measurcments and Calibration. Spccial Publication 300, Vol. 1. United States Department of Commerce, National Bureau of Standards (1969).

Box, G.E.P., Kacker, R., Nair, V., Phadke, M., Shoemaker, A., and Wu, C.F.J. (1988) 'Quality Practices in Japan', Quality Progress XXI, (3), 37-41.

Finney DJ. (1945) "Fractional replication of factorial arrangements, Annals of Eugencics, $12,291-301$.

Fisher R.A. (1945), 'A system of confounding for factors with more than two alternatives. giving completely orthogonal cubes and higher powers', Annals of Eugencies, 12, 283-290,

Leon, Ramon V., Shoemaker Anne C., and Kacker Raghu N. (1987), Performance Measures Independent of Adjustment An Explanation and Extension of Taguchi's Signal to Noise Ratios, Technometrics, August 1987, Vol. 29, No. 3., 253-285.

Box, G.F.P. (1986), "Studies in Quality Improvement: Signal to Noise Ratios, Performance Criteria and Statistical Analysis: Part J, "Technical Report II, University of Wisconsin, Centre for Quality and Productivity Improvenent.

Phadke, M.S. (1982), "Quality Engineering Using Design of Experiments," in Procecdings of the Section on Statistical Education, American Statistical Association, 11-20.

Taguchi, G., and Phadke, M.S. (1984), "Ouality Engineering Through Dssign Optimization ', in Proceedings of GLOBECOM 84 Meeting Piscataway, NJ:IEEE Communication Society, 1106-1113.

Box, George (1988), "Signal-to-Noise Ratio , Performance Criteria, and Transformation ", Technometrics, vol. 30 , no 1 .

Eartlett, M.S., and Kendall, D.G. (1946). "The Statistical Analysis of Variance-Heterogenity and the logorithmic transformation," Journal of the Royal Statistical Socicty, Scr. B, 8, 128-150.

Box, G.E.P., and Draper, N.R. (1987), Emperical Model-Building and Response Surfaces, New York: John Wiley.

Box, G.E.P., and Fung, C.A. (1983), "Some Considerations in Estimating Data Transformations," Technical Summary Report 2609, University of Wisconsin-Madison, Mathematics Research Center.

Box, G.E.P. and Meyer, R.D. (1986a) "An Analysis for Unreplicated Fractional Factorials," Technometrics, 28, 11-18.

-(1986b), "Dispersion Effects from Fractional Designs," Technometrics, 28, 19-27

Box, G.E.P., Wilson, K.B. (1951), "On the Experimental Attainment of Conditions," Journal of the Royal Statistical Society, Ser. B, 13-, 1-45.

Finney, D.J. (1951), "On the Distribution of a Variate Whose Logorithm Is Normally Distributed," Jcurnal of the Royal Statistical Society (supp.), 7, 155-161.

Gaddum, J.H. (1945), “Lognormal Distributions," Nature, 156, 463-466.

Johnson, N.L, and Kotz, S. (1970) Distributions in Statistics Cortinuous Univariate Distributions 1, Boston: Houghton Mifflin.

Curnow, R.N., and Dayananda, R.A. (1991), "The Use of Prior and Experimental Information in Setting Process Control Variables (to be published). 